\title{
WebGIS development for base flow separation and recharge estimation
}

\author{
Desenvolvimento de WebGIS para separação de escoamento e estimativa de recarga
}

\author{
Taison Anderson Bortolin ${ }^{1}$, Lucas Moraes dos Santos ${ }^{2 *}$, Vania Elisabete Schneider ${ }^{1}$, Adriano \\ Gomes da Silva ${ }^{1}$
}

\begin{abstract}
The basic flow rate is characterized by an important hydrological component being responsible for the estimation of the water recharge. Due to the difficulty of measurement, mathematical methods are used to calculate the flow separation. However, when hydrographic analysis is based on long historical series, the use of these methods becomes impracticable, making it necessary to use computational resources. A WebGIS (Web Geographical Information System) was developed for data selection and calculation of base flow separation, based on hydrological data from fluviometric stations located in the Taquari-Antas basin, located in the state of Rio Grande do Sul. A modified version of the Unified Process was used as a software development methodology. We used the MVC software architecture standard and the programming languages PHP 7.0, HTML5, JS and CSS3 for programmatic development of the constituent layers of the system. The hydrological data comes from the HIDROWEB portal, part of the National Information System on Water Resources (SNIRH), with hydrological information collected by the National Hydrometeorological Network (RHN) coordinated by the National Water Agency (ANA). The system facilitates the use of remote and distributed hydrological data, shared over the Internet, for various hydrological analyzes.
\end{abstract}

Keywords: Separation of the Base Flow - WebGIS - Base flow - Water recharge

Resumo: A vazão de escoamento de base caracteriza-se por um importante componente hidrológico sendo responsável pela estimativa de recarga aquifera. Em virtude da dificuldade de medição, são empregados métodos matemáticos para o cálculo da separação de escoamento. Contudo, quando a análise hidrográfica baseia-se em séries históricas longas, o uso desses métodos torna-se inviável, fazendo-se necessário o emprego de recursos computacionais. Neste sentido foi desenvolvido um WebGIS (Web Geographical Information System) para seleção de dados e cálculo da separação de escoamento, a partir de dados hidrológicos advindos de postos fluviométricos localizados na bacia hidrográfica Taquari-Antas, situada no estado do Rio Grande do Sul. Uma versão modificada do Processo Unificado foi usada como metodologia de desenvolvimento de software. Foi utilizado o padrão de arquitetura de software MVC e as linguagens de programação PHP 7.0, HTML5, JS e CSS3 para desenvolvimento programático das camadas constituintes do sistema. Os dados hidrológicos advém do portal HIDROWEB integrante da Sistema Nacional de Informações sobre Recursos Hıdricos (SNIRH), com informações hidrológicas coletadas pela Rede Hidrometeorológica Nacional (RHN) coordenada pela Agência Nacional de Águas (ANA). O sistema facilita o uso de dados hidrológicos remotos e distribuıdos, compartilhados pela Internet, para diversas análises hidrológicas.

Palavras-Chave: Separação de Escoamento - SIG Web - Vazão de base - Recarga hídrica

${ }^{1}$ University of Caxias do Sul, Caxias do Sul, Rio Grande do Sul, Brazil

${ }^{2}$ Federal University of Minas Gerais, Belo Horizonte, Minas Gerais, Brazil (currently)

*Corresponding author: Imsantos7@ucs.br

DOI: https://doi.org/10.22456/2175-2745.94235 • Received: 03/07/2019 • Accepted: 29/05/2020

CC BY-NC-ND 4.0 - This work is licensed under a Creative Commons Attribution-NonCommercial-NoDerivatives 4.0 International License.

\section{Introduction}

Flow data are commonly used to estimate recharge rates in humid regions, since there is an intrinsic relationship between surface and groundwater, whose systems are closely con- nected [1]. The flow of water reaching the aquifer is represented by the base flow or slow flow, which together with the direct flow form the surface flow [2]. In order to find the recharge values, it is necessary to make the separation of the base flow of the surface flow through the analysis of hydro- 
graphs obtained in fluviometric stations, and there are several methods to perform this procedure, which are described in works of [3], [4], [5], [6] and [7].

An interesting approach to flow separation is the use of digital filters [8], whose technique removes the subjectivity of manual separation, providing consistent reproducibility of results achieved. Digital filter methods are frequently used in signals processing to separate high frequency signal from low frequency signal [9]. A analogy can be done for the study of hydrological characteristics of basin such as the separation of the hydrograph in direct runoff and base flow. High frequency waves can be associated with the direct runoff, and low frequency waves to base flow [7].

To facilitate these calculations, it is important to use computational tools, which allow to reduce the calculation time, especially when it is a long period of data analysis. Over the years, some tools have been proposed, using computational techniques and resources to obtain better performance in hydrographic analyzes involving the separation of the base flow component. One of the first and widely used tools to base flow separation was developed by the United States Geological Survey(USGS), a computer program called Hydrograph Separation Program (HYSEP) [5] that uses separation methods other than digital filters. The HYSEP program is not comfortable for the user and requires a lot of user intervention in the preparation of the input data and to execute them [6]. Another computer program, also developed by the USGS, is known as RECESS, which performs the separation of the base flow using methods based on digital filters to estimate hydrological characteristics, as a recession index [10]. RECESS can perform more accurate base flow separations compared to HYSEP, creating a main recession curve (MRC) from the flow. Both software require the user to install them in order to perform hydrographic analysis.

In 2005, an Web Geographic Information System (GIS) was proposed for automated hydrographic analysis uses base flow separation methods based on digital filters. The Web based Hydrograph Analysis Tool (WHAT) uses daily flow data from the USGS web server. Currently, the WebGIS has two digital filters available: one is the digital filter [9] and ther other is the Eckhardt filter [7]. The application has too a statistical component that provide information for flow frequency analysis and time series analysis.All three systems use streamflow data from the USGS, not being easy to perform hydrological analyzes based on the separation of the base flow with data from stations other than those registered by the USGS. The systems doesn't connect to brazilian fluviometric stations, for example, and hasn't direct data in webmap on Brazil. In this case, it is necessary to prepare the hydrological data to carry out the separation of the base flow, or other estimates that the user wishes. This process can be unconfortable to user, in special, when many analyses need be done.

This paper aims to present a WebGIS tool to baseflow separation using digital filters and estimates monthly aquifer recharge, from streamflow data of fluviometric stations in
Brazil. These analyzes can aggregate information in a recharge study, which may contribute to the analysis of water location and availability in a given region. The application has a total of four (4) recursive digital filters for flow separation: algorithm of Lyne and Hollick/Nathan and Macmahon/Arnold, (also known as 1-parameter filter) [9] [8] [3], Chapman algorithm [11], Echkardt [7] and Echkardt recursive filter with maximum BFI calculated from the filter. In addition, the system provides the calculation of the monthly aquifer recharge, based on the estimated base flow. To simplify the presentation of application resources, hydrographic analyzes were based on data from fluviometric stations present in the Taquari-Antas basin, located in the northeast region of the state of Rio Grande do Sul. However, these analyzes can also be performed for other stations fluviometric, in different Brazilian watersheds.

\section{Methods}

In the present work a modified version of the development methodology known as Unified Process was used, which suggests an approach for modeling and construction of software through short iterations with testable results [12]. In order to model the application, the concept of abstract representation of processes was used to describe in an abstract way the processes that make up the system [13]. The application is based on the client/server paradigm in which a process in the local host, called client, requests services to another process, usually located in a remote host, called server [14]. The server returns the requested services to the client, at the moment that the user interacts with the application [13].

For the development of the web application it was used the MVC (Model-View-Controller) software architecture model based on the object-oriented programming paradigm (OOP), a developmental pattern that subdivides the software into components such as model, vision and controller. In this way, better quality control of the software is obtained, especially with regard to the maintenance of the system, by isolating problems inherent to a certain layer and being able to deal with them more easily.[15].

For the programmatic development of the back-end, the PHP programming language (recursive acronym for Hypertext Preprocessor), version 7.0, was used. PHP is characterized by being a specific domain language (including web development), whose code is interpreted by a PHP module present on the server side [16]. On the server, the Smarty Template Engine preprocessor [17] is also used for the generation and assembly of dynamic templates. The use of Smarty facilite in the control of the separation of the logical application and the content of its presentation, in case any change in the application logic is necessary, this will not compromise the design of the template and vice versa.

In the front-end, the user interfaces of the application were developed using HTML5 (Hypertext Markup Language), CSS3 (Cascading Style Sheets) and JavaScript (JS) styles, using framework components web, open source, Bootstrap for page design development [18]. CSS and JS were used to 
streamline and enhance user navigation in the application. In the generation of Line and BoxPlot graphs, JS C3.js and D3.js libraries were used to display dynamic and interactive data in web browsers [19].

The external OpenLayers library makes the interactive WebMap available. It is characterized as a high-performance, open-source javascript modular library with features for displaying and interacting with maps, as well as manipulating geospatial data [20]. Another factor that contributed to the choice of library was due to its free license.

In the data structure design of the application in the database, the Entity - Relationship Models (MER) and Entity - Relationship Diagrams (DER) were developed through the ER Master plugin of DERs, available for the integrated development environment Eclipse [21]. The data model demonstrates the data structure that will support the processes of the system, how the data will be organized and what relationships are to be established between them [22]. To store the hydrological data of the fluviometric stations and to obtain statistical measures on the results of the calculated base flow, the database manager PostgreSQL was used [23].

By using the Unified Process and its phases, the work was developed in four stages: design, elaboration, construction and transition. The design stage covered the bibliographic survey and looked at other systems or computer programs that performed the separation of flow and calculation of recharge. The elaboration consisted in the specification of the system, based on requirements raised in the pre-conception of the work, as well as in the modeling of the data. In the construction, the implementation of the system was carried out, the conversion of ER models to a database, the use of programming languages used to define data structures, code generation and the development of system functionality interfaces, using programming languages used in the development of web applications. Finally, in the transition, the system was made available to the end user and evaluation of the results obtained [24].

\subsection{Data modeling}

The hydrological data of the fluviometric stations comes from information system ANA, HIDROWEB. HIDROWEB is an integral tool of the National System of Information on Water Resources (SNIRH) and offers access to the database containing all the information collected by the National Hydrometeorological Network (RHN), gathering data of fluvial levels, flows, rainfall, climatology, quality water and sediment [25]. The hydrological data are public and made available for download in HIDROWEB, being subsequently updated / stored in a database.

In the design of the data model, we chose to create three (3) entities that would be responsible for storing the information. In the conversion of the DER into Data Definition Language (DDL), entities are now represented by tables, and their attributes, by columns, configuring the database as a data warehouse [26]. Each table stores a set of hydrological data and their respective information for the registered fluviometric stations. The first one is responsible for storing the measured flow values daily, these data being differentiated by the identifier of the corresponding rainfall station in the database. Another table stores information about the station: the identifier, the period that contains data, the latitude, longitude and area of the river basin. Finally, there is the table of results that store the results of the basic flow estimated for a certain historical series.

\subsection{Application modeling}

The case study used was the development of the web-geographic information system (WebGIS) to calculate base flow separation, based on hydrological data from fluviometric stations located in the Taquari-Antas basin. The system can be used by researchers in performing hydrographic analyzes for long historical series. The MVC standard was implemented in the implementation of the user interface and PHP programming languages, JS scripting, HTML markup, and CSS styles for programmatic development of the system.

In order to facilitate the process of consulting the hydrological data to the user, a WebMap was used to display fluviometric stations and hydrographic basins. To also assist in accessibility for people who do not speak the language in which the system was initially designed, a translation system was implemented. Available languages are Portuguese and English. Finally, the management of users was developed, responsible for registering new users in the system and control of access in the application through a policy of user levels. Figure 1 shows the GIS use-case diagram.

\subsection{Construction}

In the construction, the layers of the MVC standard were implemented programmatically, responsible for the core of the basic functionalities of the system, and the mathematical methods used in the separation of the flow and calculation of recharge. Basically, the Model performs queries and treatment of the hydrological data coming from the database. It is also responsible for containing the digital recursive filters for calculating the base flow and the methods that estimates the recharge for the historical series, translating the results in relation to being shown by the View. This, in turn, executes the loading logic of smarty templates (HTML and SMARTY code to run PHP), JS / CSS libraries, and on-screen client display. Finally, the Controller manages the two layers, receiving all user requests.

The Controller creates an instance of Model, responsible for initiating the connection to the database, and View that is responsible for rendering the home page. The home page is composed of a login form, where the user must enter the access information in the system. The elements that make up the home page are rendered by the Smarty Template Engine component. This component is used in the system through the View, which collects the data and actions at the execution level of the PHP code and, before returning to the client of the .html page, processes the .tpl and generates the .html file. The 


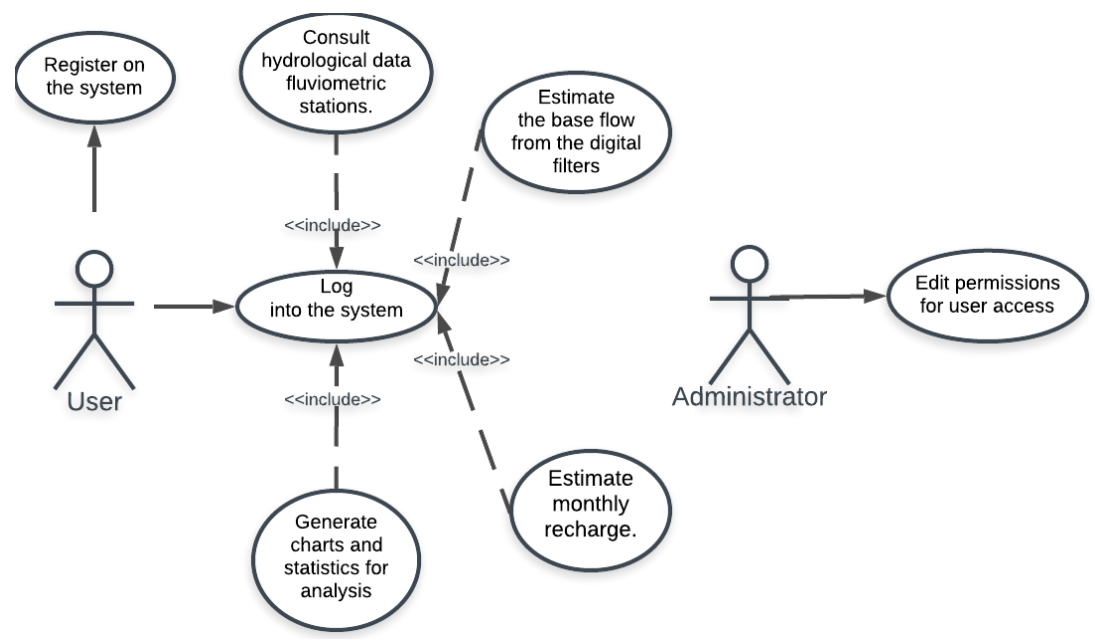

Figure 1. Use case diagram describing the proposed system functionalities.

Controller, in turn, sends a request to the Model, containing the encapsulated user information next to the HTTP request.

It is the responsibility of the Controller to also manage the process of consulting the hydrological data of the fluviometric stations and their subsequent display to the user of the application. The Controller sends to the Model the information contained in the query form, that is, the code identifying the fluviometric station and the date requested as the search key. In the Model a query is executed, the daily hidrological data coming from the database being validated and processed. With the return of the data, the Controller sends them to View that presents them to the user.

Currently, the application has a total of four (4) recursive digital filters implemented to calculate the base flow, although there are others such as fixed interval, sliding interval and local minimum that use other approaches. These methods based on digital filtering are widely used in studies that involve the separation of the base flow, because removes much of the subjectivity of manual selection, providing consistent reproducibility of the results achieved. The main methods implemented in application are: algorithm of Lyne and Hollick/Nathan and Macmahon/Arnold, (also known as 1-parameter filter) [9] [8] [3], Chapman algorithm [11], Echkardt [7] and Echkardt recursive filter with maximum BFI calculated from the filter. Some parameters must be informed to the aplication, like the constant recession $(\alpha)$ and the Basal Flow Index (BFI). Let $y_{i}$ be the surface flow (of the fluviometric station) and $i$ the time interval, the 1-parameter filter can be represented by the following equation:

$$
b_{i}=\alpha b_{i-1}+\frac{1-\alpha}{2}\left(y_{i}+y_{i-1}\right)
$$

In turn, Chapman's algorithm is given by:

$$
b_{i}=\frac{\alpha}{2-\alpha} b_{i-1}+\frac{1-\alpha}{2-\alpha} y_{i}
$$

When the user selects the Eckhardt method, it's also necessary to select the value for BFI that will be used in the calculation. The application has (3) diferent values for BFI that are the most useds: 0.8 for Perennial rivers and porous aquifers, 0.5 - Ephemeral rivers in porous aquifers and 0.25 for Perennial rivers in crystalline rock aquifers [7]. The Echkardt method is represented by the equation below:

$$
b_{i}=\frac{\left(1-B F I_{\max }\right) \alpha b_{i-1}+(1-\alpha) B F I_{\max } y_{i}}{1-\alpha B F I_{\max }}
$$

A variation of the Echkardt method, calculates $B F I_{\max }$ from the recursive filter (Equation 5). In this case, the analysis is done from the last to the first day, where $b n=y n$ (Equation 4).

$$
\begin{aligned}
& b_{i-1}^{\prime}=\frac{b_{i}^{\prime}}{\alpha} \\
& B F I_{\text {max }}=\frac{\sum_{i=1}^{N} b_{i}^{\prime}}{\sum_{i=1}^{N} y_{i}}
\end{aligned}
$$

After obtaining $B F I_{\max }$, the base flow is calculated by the Equation 3.

If the application of the above methods results in $b_{i}>y_{i}$, we consider $b_{i}=y_{i}$, subject to constraint $b_{i}<=y_{i}$ and, $b_{i}=$ $0.5 y_{i}$ for time $i=1$ [6]. When there are faults in the series $y_{i}=-1$, the calculation is restarted, eliminating the sum of $y$ the days where the -1 occurs, and the value of the base flow (b) is not calculated.

The View sends the mathematical method, the parameters for each method and the analysis period to the Controller, which in turn manages the received data and passes it on to the Model. Each one of the digital recursive filters was implemented in the Model. On the historical series, the base flow and the recharge are calculated for a given method, and the 
results are sent to the Controller. This displays the View to the user with results of the calculated base rate, after applying the filter. The Figure 2 illustrates the process sequence diagram.

In order to verify the behavior of the base flow over the historical series or to obtain descriptive statistics about the results, the user has access to two types of charts to visualize them: line chart and boxplot graph. Both charts can be filtered by user selection based on a period. In the line chart it is possible to analyze the calculated base flow in relation to the measured flow during the selected time interval, making it easier to identify trends or anomalies. For the boxplot graph it is possible to evaluate the empirical distribution of the baseline flow results monthly.

On the results obtained through the application of digital recursive filters, the system also generates some statistical measures based on the period selected by the user. The mean, standard deviation, coefficient of variation and the maximum and minimum values of the base flow for the historical series, and the months included therein, are currently calculated. The calculation of these measures is done in a database, using functions available in PostgreSQL, in order to facilitate the validation of results and decrease the complexity of PHP code.

Fluviometric stations were displayed in dotted form on a WebMap, which can be switched to a satellite or topographic type map. Reading coordinates of the database and inserting points on the map are done using javascript. The state boundaries, hydrographic basins boundaries, and the hydrological resources that are part of these are viewed in WebMap from the loading of the boundary KML (Keyhole Markup Language) file and a JavaScript Object Notation (JSON) containing the coordinates of the lines representing the hydrological resources of the basin.

User management was developed with the aim of maintaining control of users who access the application. At the moment the user wishes to register in the application, only basic information is requested for tracking analytics usage regarding the application. The user management operates based on a user level policy, where the user level "logged in" is the lowest access level and the highest level is "administrator". The highest level inherits the functions of the child. The administrator has the function of maintaining control of the users, being able to restrict the access and to exclude accounts, if necessary. The log-level user will have the main functionalities of the application, such as consulting the stored hydrological data, applying the digital recursive filters and calculating recharge for the historical series, estimating statistics on the results, and being able to switch the system language and change password. The Figure 3 illustrates the activities diagram of the system.

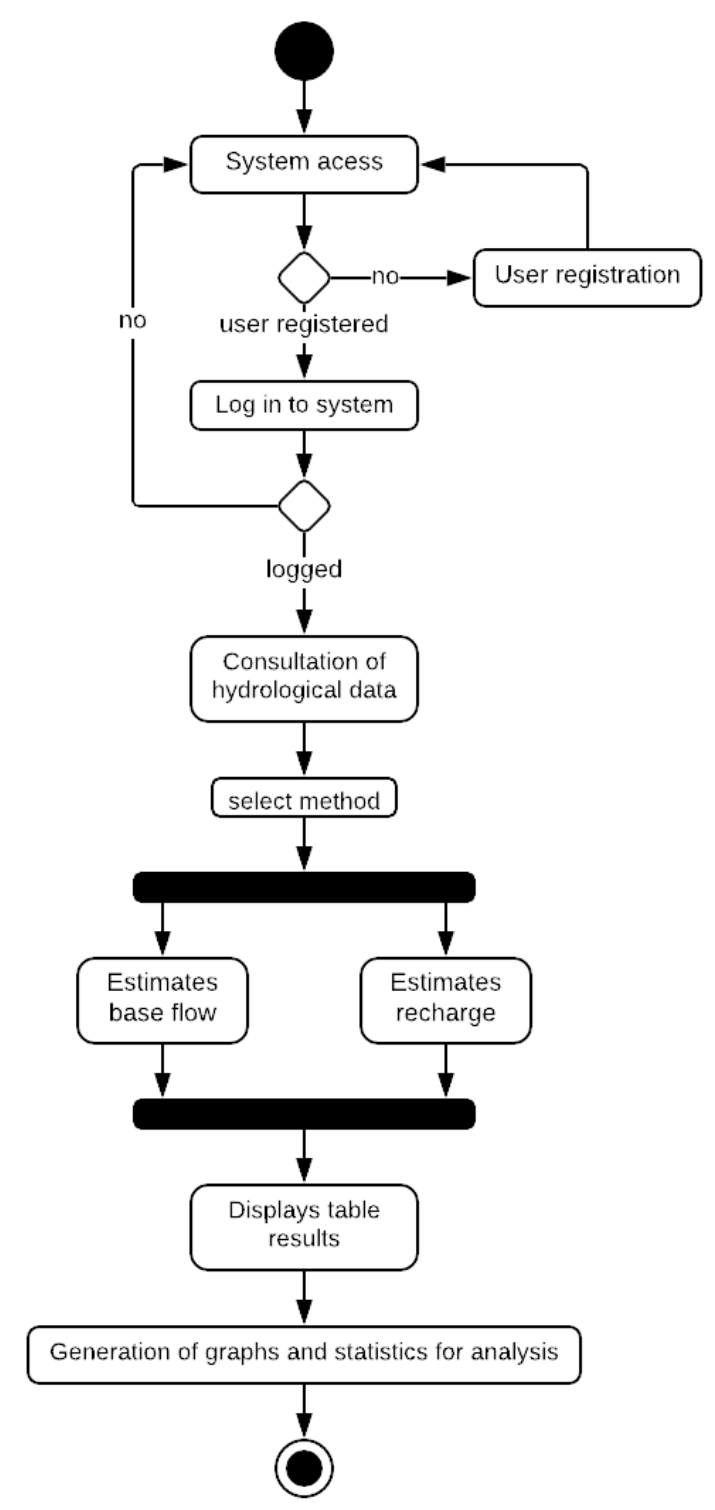

Figure 3. Activities diagram represents the flows driven by processings made by user in the system.

\section{Results and Discussion}

The Hydrographic analyzes were based on data from fluviometric stations located in the Taquari-Antas basin, located in the northeastern region of the state of Rio Grande do Sul. To use the application it is necessary to make a prior registration where information such as name, user, e-mail address, password and institution of the person will be requested. The user can change this information later, when necessary. The administrator, in turn, can block users of the application by changing the situation. Access to the application can be done from the link $\langle$ https://siambiental.ucs.br/intermediador/ $\rangle$, inserting a previously registered user and password.

The hydrological data of the fluviometric stations can be consulted from the WebMap shown in the Figure 4, where the stations are represented by points. This representation was 


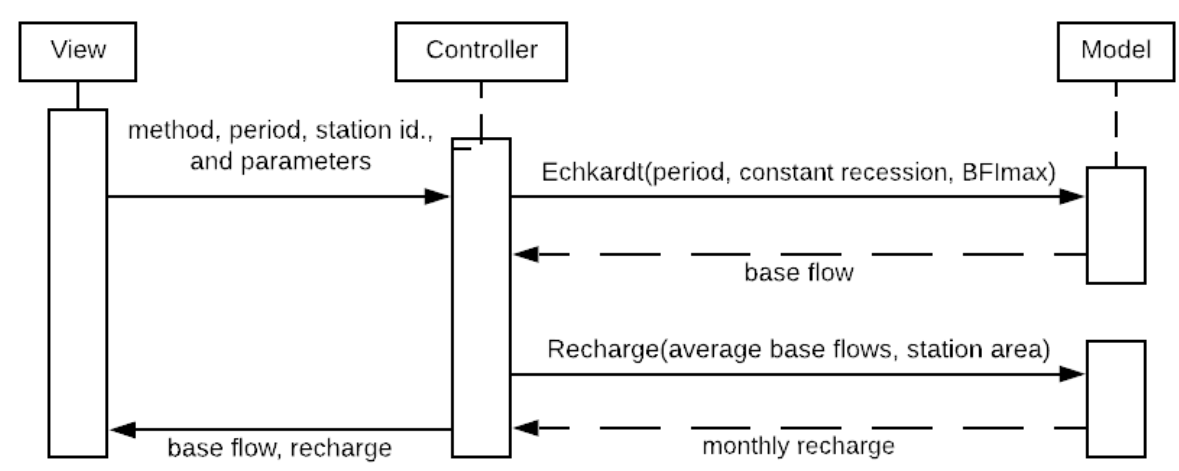

Figure 2. Process that is executed when the user choice a method for calculates the base flow and recharge. In the example, the sequence diagram is used to represents the interactions between objects in the basic flow calculation, performed through operations or methods.

developed to be familiar to those using the system considering other information systems that display hydrological data in a WebMap [27] [25] [28].

In addition to the stations, it is possible to visualize the water resources of the basin (blue lines), the boundary of the Taquari-Antas basin (lines red) and the state of Rio Grande do Sul (yellow line). When selecting a station, the user must enter the period in which to perform the analysis (Figure 5).

The hydrological data consulted for the historical series are presented to the user in a table, as shown in Figure 6. It is possible to verify the flow measured in $\mathrm{m}^{3} / \mathrm{s}$, as well as the date of measurement. This provides an alternative to loading your own data about the stations registered in the system, for it to apply mathematical methods on them [6].

\begin{tabular}{|l|l|l|}
\hline Meteorological Data & Flow rate \\
\hline & 3.25 \\
\hline $31 / 01 / 18$ & 3.25 \\
\hline $30 / 01 / 18$ & 3.93 \\
\hline $29 / 01 / 18$ & 4.84 \\
\hline $28 / 01 / 18$ & 6.43 \\
\hline $27 / 01 / 18$ & 8.09 \\
\hline $26 / 01 / 18$ & 12.07 \\
\hline $25 / 01 / 18$ & 11.79 \\
\hline $24 / 01 / 18$ & 11.22 \\
\hline $23 / 01 / 18$ & 9.8 \\
\hline $22 / 01 / 18$ & de 13067 \\
\hline Date & & \\
\hline S & & \\
\hline
\end{tabular}

Figure 6. Hydrological data were consulted for fluvial station 86420000 , in the Taquari-Antas basin. Review Period: Janury 1, 2017 to January 31, 2018.

The user must select which of the recursive digital filters will be used to estimate the base flow. In addition, the user must enter with the value of $(\alpha)$ and, depending on the method chosen, the maximum BFI value to be chosen by local hydrogeology.

The system provides the results in a table (Figure 7), and it is possible to verify, in addition to the measured flow, the daily estimated flow rate $\left(\mathrm{m}^{3} / \mathrm{s}\right)$ and the monthly recharge for the selected period. The results can be downloaded as a comma separated value (csv) file. Both options exist for giving to the user the possibility to compare the results by hand or in a spreadsheet software to results other than the obtained from the system. The csv file is intended to show the results using the same header from the table visible in the system, each column separated in it's own column in the file, for ease of use of the processed data, in light of other systems that do allow the results to be downloaded as a separate file [25]. All methods where tested against implementations of them on other platforms, including the specific hidrological models implemented on a sheet file and through WHAT [6]. These options exist in contrast to other types of methodologies involving hidrological models applied to data and then loaded manually into a GIS program [29], as they facilitate the action of applying specific types of modelling to the same subset of openly acessible hidrological data.

\begin{tabular}{|c|c|c|c|c|}
\hline Period analyzed $\leqslant$ & Total flow (m3/s) & Base flow $(\mathrm{m} 3 / \mathrm{s})$ & Months & Recharge (mm) \\
\hline 01/01/2017 & 8.65 & 4.325 & January & 17.2082 \\
\hline 02/01/2017 & 6.89 & 4.188 & February & 8.0515 \\
\hline 03/01/2017 & 9.51 & 4.0927 & March & 6.8924 \\
\hline 04/01/2017 & 10.65 & 4.0175 & April & 8.9702 \\
\hline 05/01/2017 & 16.8 & 4.0271 & May & 25.6117 \\
\hline 06/01/2017 & 11.22 & 3.9627 & June & 56.301 \\
\hline 07/01/2017 & 8.37 & 3.8643 & July & 19.2307 \\
\hline
\end{tabular}

Figure 7. The figure shows the results table, after the execution of the mathematical method for separation of base flow. The measured daily flow rate, the estimated daily basis flow rate $\left(\mathrm{m}^{3} / \mathrm{s}\right)$ by the Eckhardt mathematical method, based on a $B F I_{\text {max }}$ equal to 0.25 and a constant recession $(\alpha)$ equal to 0.96 and the monthly recharge value $(\mathrm{mm})$, calculated for the historical series. Review Period: January 1, 2017 to December 31, 2017. 
ETo Estimation \& Flow Separation - Select a point option from the menu below
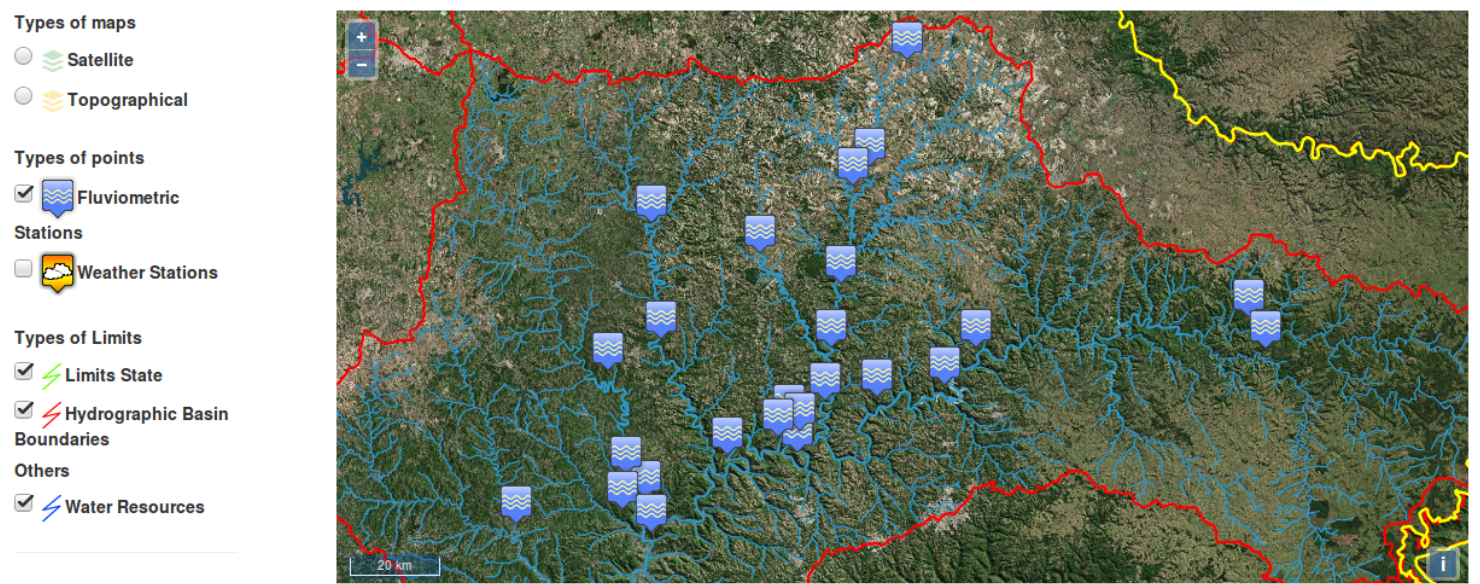

Figure 4. WebMap containing the existing fluviometric stations in the Taquari-Antas basin in the state of Rio Grande do Sul.

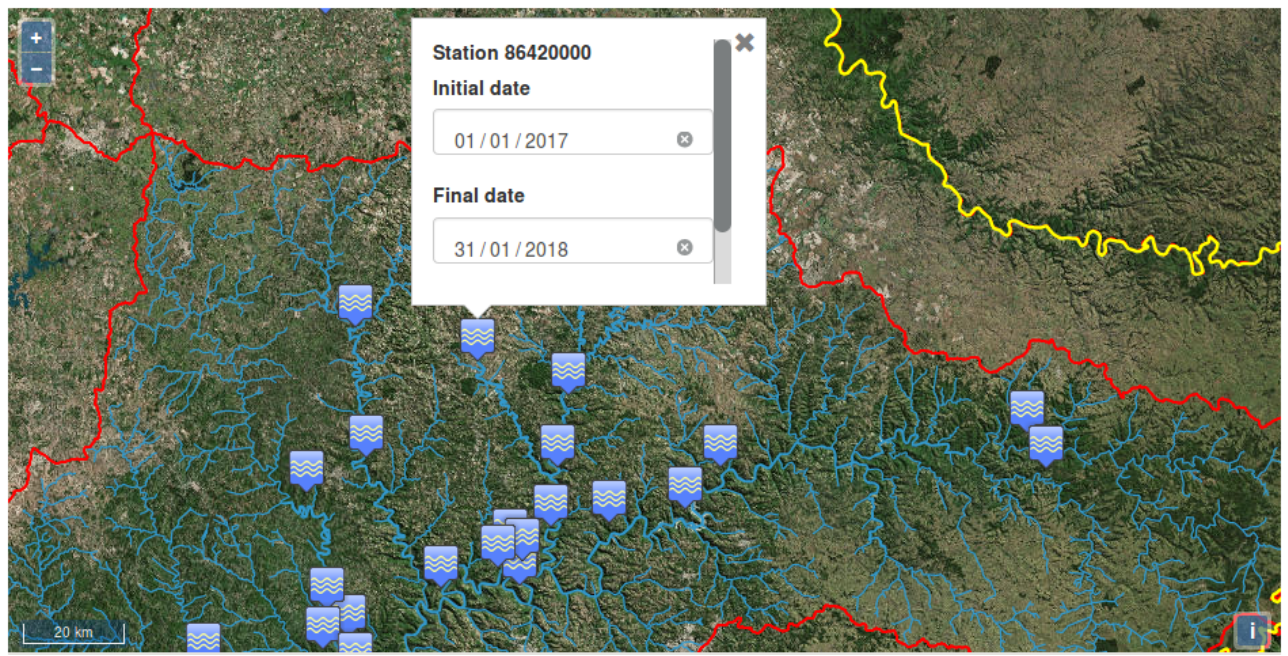

Figure 5. In the figure, it is possible to verify the selection of the station 86420000 , for a period of analysis from January 1 , 2017 to January 31, 2018.

The generation of line graphs (Figure 8) and box plot (Figure 9) can be done from the insertion of the desired period in historical series. Using charts to show the results is one way of exploring the data inside the database, as a means of online analytical processing [26]. Unlike the base flow estimation, which can be obtained for long periods of time, the generated graphs take into account only time intervals that do not exceed 1 (one) year. After testing, where the graphs were generated for different time intervals, it was arbitrarily found that the periods of analysis that allowed a better visualization of the information were contained in 1 year. These periods must necessarily be in the historical series. In this way, for a given historical series, it is possible to generate several graphs, with different periods of analysis, exploring the concept of using different slices of historical data for different analytical decision making [26].

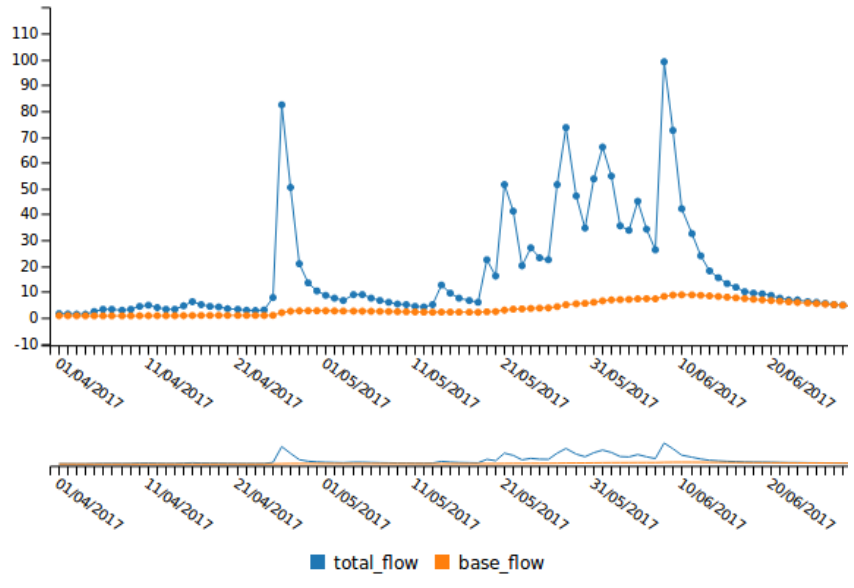

Figure 8. Time line chart showing the behavior of the base flow $\left(\mathrm{m}^{3} / \mathrm{s}\right)$ in relation to the measured flow $\left(\mathrm{m}^{3} / \mathrm{s}\right)$, throughout the historical series. It is possible to verify an increase in base flow in May, and in early June, due to the increase in precipitation for that period.

R. Inform. Teór. Apl. (Online) • Porto Alegre •V. $27 \bullet$ N. 3 • p.68/71 • 2020 


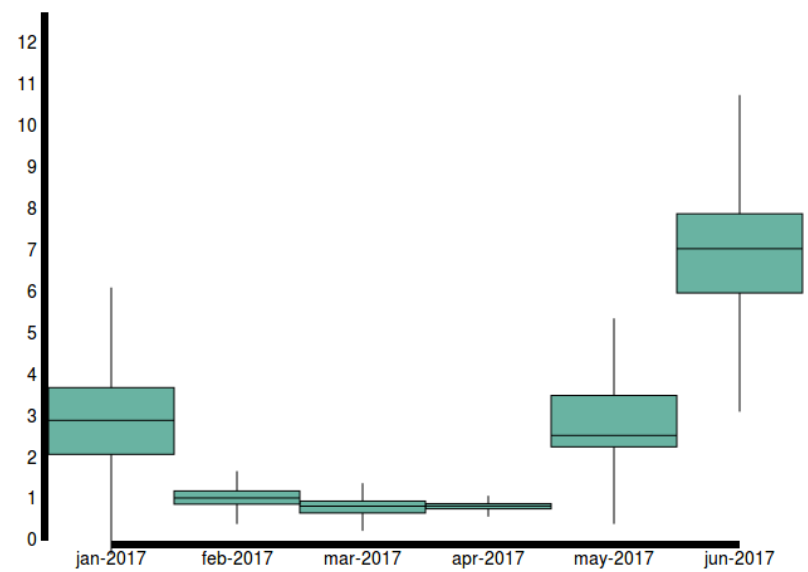

Figure 9. Chart box plot representing the variation of the monthly base flow $\left(\mathrm{m}^{3} / \mathrm{s}\right)$. Review Period: January 1, 2017 to June 31, 2017.

On the results of the estimated base flow, statistics are also provided that allow the user to do not only a monthly analysis of the base flow, but also for the whole historical series (Figure 10).

\begin{tabular}{|c|c|c|c|c|c|}
\hline Month-Year & Mean & Maximum & Minimum & Standard deviation & Coefficient of variation \\
\hline $2017-12$ & 1.646 & 2.175 & 1.341 & 0.285 & 0.173 \\
\hline $2017-11$ & 2.174 & 2.677 & 1.757 & 0.227 & 0.104 \\
\hline $2017-10$ & 2.516 & 3.977 & 0.770 & 1.303 & 0.518 \\
\hline $2017-09$ & 0.916 & 1.167 & 0.780 & 0.105 & 0.115 \\
\hline $2017-08$ & 1.181 & 1.388 & 0.886 & 0.149 & 0.126 \\
\hline $2017-07$ & 2.276 & 3.996 & 1.222 & 0.818 & 0.359 \\
\hline $2017-06$ & 6.886 & 8.856 & 4.160 & 1.344 & 0.195 \\
\hline $2017-05$ & 3.031 & 5.969 & 2.111 & 1.120 & 0.370 \\
\hline $2017-04$ & 1.097 & 2.697 & 0.732 & 0.653 & 0.595 \\
\hline $2017-03$ & 0.816 & 1.020 & 0.602 & 0.150 & 0.184 \\
\hline $2017-02$ & 1.055 & 1.524 & 0.721 & 0.226 & 0.214 \\
\hline $2017-01$ & 2.907 & 4.325 & 1.580 & 0.890 & 0.306 \\
\hline
\end{tabular}

Figure 10. Statistics obtained for the monthly base flow. Review Period: January 1, 2017 to December 31, 2017.

Regarding the development methodology used, it was found that the Unified Process allowed the progress of the project's steps without compromising the quality of the system. With the development organized in iterations, the programming analysis and testing activities were developed almost concurrently. At the end of each iteration, the result was a partial system whose specifications were re-analyzed by the environmental area and frequently evolved, based on the knowledge acquired. In this way, some benefits were obtained, such as: early mitigation of errors related to the coding of algorithms based on digital filters, from the validation of the estimated base flow and recharge results; frequent involvement of the environmental area and immediate adaptation of new specifications to the project, providing the refinement of the system; better management of the complexity of project stages, avoiding development overload; improves the quality of the system at the end of each iteration. In this sense, the Unified Process of development progresses through a series of structured cycles, and instead of speculating about requirements or correct projects, it approaches with greater precision than what the customer really needs [12].

Real projects hardly follow a sequential flow, as occurs in the approach adopted by the cascade methodology [30]. When defining which tests and validations would be performed only after the completion of previous steps, any changes in the coding, or even in the design, would become more complex. In the case of the prototyping methodology, developing a prototype would not necessarily be the best option. In some cases, the development team may yield to customer requirements, who, in turn, believe that the prototype already solves the problem. Thus, the final quality and maintenance of the system can be compromised.

\section{Conclusion}

Problems pertaining to the field of hidrology can be modeled and implemented in an Information System [31]. Especifically in relation to the application of mathematical methods applied on data [32]. Data Warehouses may aswell be used to store hydrological data [33]. Information Systems and Data Warehouses may be combined to deliver OLAP over data, for the decision making process [34]. In this sense, the choice of the development of a GIS was to maximize the efficiency of the planning and decision making based on the exposure of the different stations in the WebMap, through the interactivity with these objects, taking advantage of the previous knowledge about the location of the stations and the possibilities of provided by the responsibilities of a GIS. The use of GIS also aimed at providing efficient means for the user to manipulate the geographic data made available through the tool, due to the integration with data from the National Water Agency (ANA).

With regard to the storage of information from ANA, a Data Warehouse was employed due to the data format premade available for the implementation of the system, being this data of a historical period, remaining unchanged after its storage. The exploitation of this data, being the purpose of the system implementation, is in line with the possibility of the analysis of temporal data of a Data Warehouse. Thus, in order to explore the analytical character of an implementation of an IS and a Data Warehouse, mathematical methods for manipulating flow data were implemented in order to show results to simplify the application of such mathematical models in periods of data for the stations whose data are available for public consultation, as well as provide a tool to facilitate comparative analysis among such methods. The development of the system as a GIS provides the user with simplified and remote access to hydrological data from fluviometric stations, also serving as a useful tool for analyzing flow separation results, providing technical support for decision making.

The system facilitates hydrographic analysis involving flow separation, for data from river stations present in river basins in Brazil. These analyzes add information in a water recharge study, which may contribute to the analysis of water location and availability in the region. Future implementations aim to provide to the user the possibility to select two or 
more filter algorithms to compare the results of them in the same chart. In addition, there is the possibility of expanding the Data Warehouse with the insertion of new Data Marts (modules) in it, to explore other topics pertinent to hydrology and which enjoy data from free bases, in view of this as a plan of development.

\section{Author contributions}

Taison Anderson Bortolin: Substantial contributions to the conception of the work; data acquisition, analysis and interpretation; creation of new software used at work; wrote the paper and carried out a substantial review;

Lucas Moraes dos Santos: Substantial contributions to the conception of the work; data analysis and interpretation; creation of new software used at work; wrote the paper and carried out a substantial review;

Vania Elisabete Schneider: Substantial contributions to the conception of the work; wrote the paper and carried out a substantial review;

Adriano Gomes da Silva: Analysis and interpretation of data; creation of new software used at work;

\section{References}

[1] WINTER, T. et al. Ground water and surface water; a single resource. US Geological Survey, n. 1139, 1998.

[2] CHOW, V. T. Applied Hydrology. New York (NY): McGraw-Hill, 1988. 585 p.

[3] ARNOLD, J. et al. Automated base flow separation and recession analysis techniques. Ground Water, v. 33, n. 6, p. 1010-1018, 1995.

[4] ARNOLD, J.; ALLEN, P. Validation of automated methods for estimating baseflow and groundwater recharge from stream flow records. Journal of the American Water Resources Association, v. 35, n. 6, p. 411-424, 1999.

[5] SLOTO, R.; CROUSE, M. Hysep: A computer program for stream flow hydrograph separation and analysis. U.S. Geological Survey, Reston, Virginia (VA), p. 3994-4040, 1996.

[6] LIM, K. J. et al. Automated web GIS based hydrograph analysis tool, WHAT. JOURNAL OF THE AMERICAN WATER RESOURCES ASSOCIATION, v. 41, n. 6, p. 1407-1416, 2005.

[7] ECKHARDT, K. How to construct recursive digital filters for baseflow separation. HYDROLOGICAL PROCESSES, v. 19, n. 2, p. 507-515, 2005.

[8] NATHAN, R.; MCMAHON. Evaluation of automated techniques for base flow and recession analyses. Water Resources Research, v. 26, n. 7, p. 1465-1473, 1990.

[9] LYNE, V.; HOLLICK, M. Stochastic time-variable rainfall-runoff modelling. Institution of Engineers, Canberra, Australia, p. 89-93, 1979.
[10] RUTLEDGE, A.; MESKO. Estimated hydrologic characteristics of shallow aquifer systems in the valley and Ridge, the Blue Ridge, and the Piedmont physiographic provinces based on analysis of streamflow recession and base flow. U.S. Geological Survey, USA, p. 1-58, 1996.

[11] CHAPMAN, T. A comparison of algorithms for stream flow recession and base flow separation. Hydrological Processes, v. 13, n. 5, p. 701-714, 1999.

[12] LARMAN, C. Applying UML and Patterns: An Introduction to Object-Oriented Analysis and Design and Iterative Development. Upper Saddle River (NJ): Prentice Hall, 2005.

[13] SOMMERVILLE, I. Software Engeneering. 8. ed. [S.1.]: Pearson Addison Wesley, 2007.

[14] FOROUZAN, B. A. Data Communications and Networking. New York (NY): McGraw-Hill, 2007.

[15] HASAN, S. S.; ISAAC, R. K. (Ed.). An integrated approach of MAS-CommonKADS, Model-View-Controller and web application optimization strategies for web-based expert system development. 1. ed. [S.1.]: Elsevier BV, 2011. v. 38.

[16] PHP. PHP: Hypertext Preprocessor. 1995. Accessed: February 03, 2019. Disponível em: 〈http://php.net/〉.

[17] SMARTY. Chapter 1. What is Smarty? Part I. Getting Started. 2010. Accessed: February 03, 2019. Disponível em: 〈https://www.smarty.net/docs/en/what.is.smarty.tpl $\rangle$.

[18] BOOTSTRAP. Bootstrap. 2013. Accessed: February 03, 2019. Disponível em: 〈https://getbootstrap.com/〉.

[19] MURRAY, S. Interactive Data Visualization for the Web. 1. ed. Sebastopol (CA): O'Reilly Media, Inc., 2013.

[20] OPENLAYERS. Basic Concepts. 2006. Accessed: February 03, 2019. Disponível em: 〈https://openlayers.org/en/latest/ doc/tutorials/concepts.html $\rangle$.

[21] ERMASTER. What is ERMaster ?. 2013. Accessed: February 03, 2019. Disponível em: 〈http://ermaster. sourceforge.net//.

[22] DEBASTIANI, C. A. Definindo Escopo em Projetos de Software. São Paulo (SP): Novatec, 2015.

[23] POSTGRESQL. What is PostgreSQL ?. 1999. Accessed: February 03, 2019. Disponível em: 〈https://www.postgresql. org/about/ $/$.

[24] SCHACH, S. R. Object-Oriented Classical Software Engineering. 7. ed. New York (NY): McGraw-Hill, 2007.

[25] HIDROWEB - Sistema de Informações Hidrológicas. Accessed: May 23, 2019. Disponível em: 〈http://www.snirh. gov.br/hidroweb/publico/mapa_hidroweb.jsf $\rangle$.

[26] ELMASRI, R.; NAVATHE, S. B. Fundamentals of Database Systems. 8. ed. [S.1.]: Addison-Wesley, 2011.

[27] CEMADEN. Mapa Interativo da Rede Observacional para Monitoramento de Risco de Desastres Naturais. Accessed: May 23, 2019. Disponível em: 〈http://www.cemaden. gov.br/mapainterativo/>. 
[28] SIOUT - Sistema de Outorga de Água do Rio Grande do Sul. Accessed: May 23, 2019. Disponível em: 〈http://www. siout.rs.gov.br/sig/ $>$.

[29] CABRAL, S. L. et al. HYDROLOGIC AND HYDRAULIC MODELLING INTEGRATED WITH GIS: A STUDY OF THE ACARAÚ RIVER BASIN - CE. Journal of Urban and Environmental Engineering, João Pessoa (PB), v. 8, n. 2, p. 167-174, 2015.

[30] PRESSMAN, R. S. Engenharia de Software. 6. ed. São Paulo (SP): McGraw Hill/Nacional, 2006.

[31] TSIHRINTZIS, V. A.; HAMID, R.; FUENTES, H. R. Use of geographic information systems (gis) in water resources: A review. Water Resources Management, v. 10, n. 4, p. 251-277, Aug 1996. Disponível em: 〈https://doi.org/10. 1007/BF00508896>.
[32] KAMBLE, B. D. Hydrological Information System: Integrated System for Modeling, Simulation, Analysis, and Distribution of Climate and Hydrology Data. Tese (Doutorado), Lincoln, NB, USA, 2012. AAI3504937.

[33] CHEN, D.; WANG, W.; YANG, H. Application research on data warehouse of hydrological data comprehensive analysis. In: 2010 3rd International Conference on Computer Science and Information Technology. [S.l.: s.n.], 2010. v. 9, p. 140-143.

[34] PICK, J. B. Data warehouses and gis. In: _. Encyclopedia of GIS. Cham: Springer International Publishing, 2017. p. 445-452. Disponível em: 〈https://doi.org/10.1007/ 978-3-319-17885-1_254〉. 